\title{
Efficacy and Treatment Costs of Monotherapy with bDMARDs in the Treatment of Rheumatoid Arthritis in Patients Intolerant to or Inappropriate to Continue Treatment with Methotrexate
}

\author{
Alberto Batticciotto • Roberto Ravasio • Marta Riva • \\ Piercarlo Sarzi-Puttini
}

Received: June 1, 2016/ Published online: July 4, 2016

(c) The Author(s) 2016. This article is published with open access at Springerlink.com

\begin{abstract}
Introduction: Only limited information is available on cost efficacy of the various biological agents used to treat patients with rheumatoid arthritis with intolerance or for whom it would be inappropriate to continue treatment with conventional agents. We estimated the efficacy and treatment costs of monotherapy with biological agents in the treatment of this group of patients.
\end{abstract}

Methods: Data from two previous meta-analyses in the treatment of patients who are intolerant to methotrexate (MTX), or for whom it would be inappropriate to continue treatment with MTX was used. Pharmacoeconomic comparison between

Enhanced content To view enhanced content for this article go to http://www.medengine.com/Redeem/FED4 F060197B5A08.

A. Batticciotto · P. Sarzi-Puttini

Rheumatology Unit, L. Sacco University Hospital, Milan, Italy

R. Ravasio ( $\square)$

Health Publishing and Services Srl, Milan, Italy

e-mail: rravasio@aboutpharma.com

M. Riva

Rheumatology Unit, San Gerardo Hospital, Monza, Italy biological agents was carried out to estimate the respective cost for the number needed to treat (NNT) compared to placebo using both American College of Rheumatology (ACR) and European League Against Rheumatism (EULAR) criteria. The analysis involved the four agents approved in Italy: adalimumab (ADA), etanercept (ETN), certolizumab pegol (CTZ), and tocilizumab (TCZ). A six-month period was considered sufficient to understand the most important differences in efficacy and treatment costs. Direct medical costs, including pharmacological therapy, administration and monitoring were considered.

Results: Using both ACR and EULAR criteria, TCZ (intravenous [iv]/subcutaneous [sc]) had a lower NNT than the other agents. The difference in NNT observed for ETN was more pronounced with EULAR criteria, whereas in the comparison with ADA, the most sensitive differences were observed with ACR criteria. ETN had the lowest treatment cost (€6402.19), followed by ADA (€6698.84), TCZ sc (€6887.61), and TCZ iv (€7130.83). TCZ sc had the lowest cost for NNT with both ACR and EULAR criteria. The differences compared to ETN and ADA were 
significant and related with the level of efficacy. Sensitivity analysis confirmed these results.

Conclusion: TCZ is a cost-effective therapeutic option compared to other tumor necrosis factor- $\alpha$ inhibitors (ADA, ETA, CTZ) as first-line monotherapy for patients who are intolerant to MTX, or for whom it is inappropriate to continue treatment with MTX.

Funding: Roche SpA.

Keywords: Adalimumab; Biological agents; Certolizumab; Etanercept; Number needed to treat (NNT); Pharmacoeconomics; Rheumatoid arthritis; Rheumatology; Tocilizumab

\section{INTRODUCTION}

Rheumatoid arthritis (RA) is a systemic autoimmune disease characterized by chronic inflammation of synovial joints $[1,2]$. The persistence of intra-articular inflammation causes cartilage destruction and bone erosion, leading to peripheral joint deformation and disability. Joint damage and functional loss are present at the very early stages, but the rate of progression of disease varies among individual patients $[3,4]$.

The global prevalence of RA in the adult population is estimated to be $0.5-1 \%$; however, it appears to depend greatly on the geographical area (Japan 0.2\%, Netherlands 1-1.5\%, Scandinavian Peninsula 3\%, Spain 0.5\%, and United States 1\%) [5, 6]. In Italy, two observational studies estimated a prevalence of $0.33 \%$ in Liguria and $0.31 \%$ in Lombardy $[5,7]$. Despite its relatively low prevalence, RA is associated with significant disability and high economic and social impact [8]. Conventional disease-modifying anti-rheumatic drugs (cDMARDs), such as methotrexate (MTX), represent the first-line of treatment, whereas biologic disease-modifying anti-rheumatic drugs (bDMARDs) constitute second-line strategy and are recommended in all patients with inadequate response or who are intolerant, or for whom it would be inappropriate to continue treatment with cDMARDs $[9,10]$.

The use of bDMARDs has brought significant progress in RA therapy as they allow a very high proportion of patients to achieve clinical remission or low disease activity, with a concomitant reduction of long-term disability [11-15]. In most cases, bDMARDs-including adalimumab (ADA), abatacept, infliximab, etanercept (ETN), certolizumab (CTZ), golimumab, rituximab, and tocilizumab (TCZ) - are administered in combination with MTX for the treatment of moderate to severe RA in adult patients with an inadequate response to MTX. In other cases, some of these agents (ADA, ETN, CTZ, and TCZ) can be used as monotherapy in the treatment of RA patients who are intolerant to MTX, or for whom it is inappropriate to continue treatment with MTX.

By focusing attention on this latter therapeutic indication, the aim of this analysis was to estimate the efficacy and treatment costs of monotherapy with bDMARDs in treatment of RA patients who are intolerant to MTX, or for whom it is inappropriate to continue MTX treatment.

\section{METHODS}

\section{Clinical Data}

The main criteria for evaluating improvement or clinical response to pharmacological treatment for RA are those recommended by the American College of Rheumatology (ACR) and the European League Against Rheumatism (EULAR). Both these societies have reached consensus regarding the minimum number of 
active disease variables (core set) to be measured to evaluate the efficacy of treatment [16]. These variables include: number of painful and swollen joints, measurement of residual functional abilities, serological evaluation of acute phase reactants (erythrocyte sedimentation rate [ESR] and C-reactive protein [CRP]), and opinion of disease activity expressed by both the doctor and patient, in addition to that on the intensity of pain perceived by the patient [17]. EULAR criteria are based on absolute values and on changes in the disease activity score (DAS)/DAS28 compared to baseline (assessment and classify response to treatment as good, moderate, or absent) [18]. ACR criteria evaluate the improvement $(20 \%, 50 \%, 70 \%)$ in all core set variables [16]. Despite being different, both criteria are used routinely in clinical trials.

The present economic analysis is based on two meta-analyses that focused on the efficacy of bDMARD monotherapy for the treatment of RA $[19,20]$. The first, carried out by Orme et al. [20] using the main medical databases (Medline, Embase, and Cochrane Library), considered all randomized phase 2 and 3 clinical studies on the treatment of patients with RA using ACR (ACR 20, 50, and 70) criteria as the clinical endpoint. In line with the main objective of the present analysis, Table 1 shows the details of the estimated efficacy data (vs. placebo) for the bDMARDs used in monotherapy.

The second meta-analysis, which is a "final appraisal determination" from the UK National Institute for Health and Care Excellence (NICE) [19], available online, evaluated the efficacy of bDMARDs in the treatment of treatment-naive patients with RA or those who failed previous treatment with cDMARDs using EULAR criteria. The efficacy results (vs. placebo) are shown in Table 2 and refer to biologics used as monotherapy [19].

Table 1 ACR 20, 50, and 70: bDMARDs monotherapy vs. placebo [20]

\begin{tabular}{lccc}
\hline Treatments & ACR 20 & ACR 50 & ACR 70 \\
\hline Placebo & $14.1 \%(11.1 \%, 17.7 \%)$ & $5.9 \%(3.9 \%, 8.7 \%)$ & $1.3 \%(0.6 \%, 3.1 \%)$ \\
ADA $40 \mathrm{mg} / \mathrm{EOW}$ & $44.8 \%(32.4 \%, 57.9 \%)$ & $23.2 \%(12.5 \%, 39.8 \%)$ & $13.2 \%(3.6 \%, 42.8 \%)$ \\
ETN $2 \times 25 \mathrm{mg} /$ week & $66 \%(45.6 \%, 83.4 \%)$ & $46.4 \%(21.3 \%, 78.1 \%)$ & $20.9 \%(3.3 \%, 92 \%)$ \\
TCZ $8 \mathrm{mg} / \mathrm{kg} / 4$ weeks & $81.1 \%(61 \%, 92.8 \%)$ & $74.7 \%(31.2 \%, 98.3 \%)$ & $43 \%(5.4 \%, 98.9 \%)$ \\
\hline
\end{tabular}

$A C R$ American College of Rheumatology, $A D A$ adalimumab, $b D M A R D s$ biologic disease-modifying anti-rheumatic drugs, $E O W$ every other week, ETN etanercept, $T C Z$ tocilizumab

Table 2 EULAR criteria: bDMARD monotherapy vs. placebo [19]

\begin{tabular}{llr}
\hline Treatments & Moderate response & Good response \\
\hline Placebo & $50 \%(7 \%, 94 \%)$ & $12 \%(5 \%, 65 \%)$ \\
ADA $40 \mathrm{mg} / \mathrm{EOW}$ & $76 \%(33 \%, 98 \%)$ & $31 \%(5 \%, 78 \%)$ \\
ETN $2 \times 25 \mathrm{mg} /$ week & $71 \%(12 \%, 99 \%)$ & $26 \%(1 \%, 87 \%)$ \\
TCZ $8 \mathrm{mg} / \mathrm{kg} / 4$ weeks & $93 \%(77 \%, 99 \%)$ & $61 \%(32 \%, 88 \%)$ \\
\hline
\end{tabular}

$A D A$ adalimumab, $b D M A R D$ s biologic disease-modifying anti-rheumatic drugs, EOW every other week, ETN etanercept, EULAR European League Against Rheumatism, $T C Z$ tocilizumab 
Both meta-analyses are identified TCZ as the most efficacious monotherapy in the treatment of patients who are intolerant to MTX, or for whom it would be inappropriate to continue treatment with MTX $[19,20]$.

\section{Number Needed to Treat}

Methodological progresses have led to the development of instruments specific to the field of pharmacoeconomic evaluation, with the final aim to calculate the incremental cost-effectiveness ratio (ICER). This indicator allows decision-makers to know at what additional cost it is possible to purchase an additional unit of result, expressed in the form of quality-adjusted life years (QALY). Once the ICER per QALY has been calculated, to verify its acceptability, it must be compared with a reference "threshold value", which according to AIES (Associazione Italiana di Economia Sanitaria) guidelines, should be $€ 40,000$ [21]. It is important to remember that the purpose of this threshold which is calculated considering quality-adjusted or unadjusted survival as its outcome is to express the decision-maker's willingness to pay to obtain an additional unit of health (QALY).

In this specific case, the two meta-analyses considered $[19,20]$ did not provide, among the various outcomes evaluated, any results in terms of simple life years (LY) or QALY. Thus, an incremental analysis approach can be applied, since it would not have been possible to calculate an ICER per life year gained to be compared with the reference threshold value; however, it would have been possible to determine an ICER for an 'intermediate' outcome (e.g., ICER per patient at the therapeutic target), but that cannot be compared with the reference threshold value [21].
To overcome the problem of finding a result indicator without being able to evaluate its quality, it was decided to perform a pharmacoeconomic comparison between bDMARDs with the aim of estimating the respective cost for the number needed to treat (NNT) compared to placebo [22, 23]. This indicator represents the number of patients to be treated to obtain a given therapeutic benefit, or in this case the number of patients that has to be treated with a specific bDMARD compared to placebo to obtain a responder, in which efficacy is measured using both ACR and EULAR criteria. Hence, by multiplying this indicator by the relative cost of treatment, the cost of NNT associated with the bDMARDs can be calculated.

\section{Time Horizon and Perspective}

When comparing two or more healthcare technologies for pharmacoeconomic purposes, national [21] and international guidelines $[25,26]$ recommend the use of a time horizon suited to understand all the main differences expressed in terms of both outcomes and treatment costs. Given that in the majority of the clinical studies considered in the two meta-analyses, the median follow-up efficacy period was 24 weeks; it was decided that for this analysis, a 6-month period would be adequate to understand the most important differences in efficacy and treatment costs.

The economic analysis was conducted from a National Health Service (NHS) perspective.

\section{bDMARDs}

As mentioned above, the aim of this analysis was to explore the efficacy and treatment costs of bDMARDs with an authorized indication as monotherapy for patients who are intolerant to 
Table 3 Mean 6-month cost of treatment with bDMARD monotherapy

\begin{tabular}{lllcll}
\hline bDMARDs & Dose & Pack & Pack price & Monthly cost & 6-month cost \\
\hline Tocilizumab (iv) & Every 4 weeks & $8 \mathrm{mg} / \mathrm{kg}$ & $€ 149.25$ & $€ 1131.77$ & $€ 6790.65$ \\
Tocilizumab (sc) & $1 \mathrm{syr} \mathrm{OW}$ & $4 \mathrm{syr} 162 \mathrm{mg}$ & $€ 1044.17$ & $€ 1131.19$ & $€ 6787.13$ \\
Etanercept (sc) & $50 \mathrm{mg} \mathrm{OW}$ & $4 \mathrm{syr} 50 \mathrm{mg}$ & $€ 969.49$ & $€ 1050.29$ & $€ 6301.71$ \\
Adalimumab (sc) & $40 \mathrm{mg} \mathrm{EOW}$ & $2 \mathrm{syr} 40 \mathrm{mg}$ & $€ 1015.13$ & $€ 1099.73$ & $€ 6598.36$ \\
Certolizumab (sc) & $200 \mathrm{mg} \mathrm{EOW}$ & $2 \mathrm{syr} 200 \mathrm{mg}$ & $€ 920.55$ & $€ 997.26$ & $€ 5983.58$ \\
\hline
\end{tabular}

bDMARDs biologic disease-modifying anti-rheumatic drugs, $E O W$ every other week, iv intravenous, $O W$ once a week, sc subcutaneous, syr syringe

a Assuming an average patient weight of $70 \mathrm{~kg}$

MTX, or for whom it is inappropriate to continue treatment with MTX. In Italy, there are currently four bDMARDs with this indication: ADA, ETN, CTZ, and TCZ. The first three, administered via a subcutaneous (sc) route, are tumor necrosis factor (TNF)- $\alpha$ inhibitors, while the fourth, administered via both the sc and intravenous (iv) routes, is an inhibitor of the interleukin-6 (IL-6) receptor [19].

The two meta-analyses only provided efficacy data for three of the four bDMARDs: ADA, ETA, and TCZ. For this reason, CTZ was excluded from the base case analysis and considered only in the sensitivity analysis (see relevant paragraph in Sensitivity Analysis section). On the basis of the results of the SUMMACTA study, which demonstrated that TCZ sc (162 mg injection a week) and TCZ iv $(8 \mathrm{mg} / \mathrm{kg}$ every 4 weeks) have comparable efficacy, the two meta-analyses did not distinguish between the two formulations [24].

\section{Treatment Cost}

Direct medical costs, such as pharmacological therapy (bDMARDs), administration and monitoring were only considered. Other direct medical costs (i.e., adverse events) were excluded since they were assumed similar to all bDMARDs considered.

Table 3 indicates the mean 6-month cost of the monotherapies included in the comparison. The per pack cost of the bDMARDs is the ex-factory price including the temporary discounts imposed by national law (AIFA Resolution of 3 July 2006, Official Gazette N. 156 of 7 July 2006, and subsequent AIFA Resolution of 9 February 2007, Official Gazette N. 57 of 9 March 2007 and extensions thereof), excluding any other discounts agreed with NHS facilities. These costs were calculated considering the doses indicated in the respective Summaries of Product Characteristics.

In line with the procedures implemented in Italy, the cost of administration was considered only for the bDMARDs administered intravenously, whereas no cost was assumed for sc drugs. The charge applied for an iv infusion was considered to be $€ 11.62$, as indicated by the national list of charges for specialist outpatient healthcare services [27].

The healthcare resource consumption associated with monitoring activities was calculated using the data indicated in a recent national experience comparing TCZ iv with ADA sc [28]. Table 4 indicates the healthcare 
Table 4 Monitoring: mean 6-month costs [28]

\begin{tabular}{|c|c|c|c|c|c|}
\hline \multirow[t]{2}{*}{ Healthcare services } & \multirow[t]{2}{*}{ Unit cost } & \multicolumn{2}{|l|}{ bDMARDs IV } & \multicolumn{2}{|l|}{ bDMARDs SC } \\
\hline & & 6-month service & 6-month cost & 6-month service & 6-month cost \\
\hline Visit & $€ 20.66$ & 6 & $€ 123.96$ & 2 & $€ 41.32$ \\
\hline Complete blood count & $€ 3.17$ & 6 & $€ 19.02$ & 2 & $€ 6.34$ \\
\hline ESR and CRP & $€ 5.82$ & 6 & $€ 34.92$ & 2 & $€ 11.64$ \\
\hline Hepatic function & $€ 2.04$ & 6 & $€ 12.24$ & 2 & $€ 4.08$ \\
\hline Urea, electrolytes, and creatinine & $€ 9.57$ & 6 & $€ 57.42$ & 2 & $€ 19.14$ \\
\hline Chest X-ray & $€ 15.49$ & 1 & $€ 15.49$ & 1 & $€ 15.49$ \\
\hline Cholesterol & $€ 2.47$ & 3 & $€ 7.41$ & 1 & $€ 2.47$ \\
\hline Total (6 months) & & & $€ 270.46$ & & $€ 100.48$ \\
\hline
\end{tabular}

bDMARDs biologic disease-modifying anti-rheumatic drugs, CRP C-reactive protein, ESR erythrocyte sedimentation rate, $I V$ intravenous, $S C$ subcutaneous

resource consumption and mean costs for monitoring activities, making a distinction between sc and iv regimens, for the 6-month observation period. Healthcare services were calculated using the corresponding NHS charges [27]. The cost of 6 months of monitoring associated with an iv bDMARD was almost three times that estimated for sc bDMARD ( $€ 270.46$ vs. $€ 100.48)$.

\section{Sensitivity Analysis}

The sensitivity analysis was carried out with the aim of evaluating the degree of uncertainty of the results of the base case [29]. It focused on the key variables of the analysis, i.e., the efficacy data obtained from the two meta-analyses, which made it possible to determine the mean cost for the NNT for the biologics considered. A first part of the sensitivity analysis was conducted by simultaneously varying each efficacy parameter to observe its effect on the mean cost per NNT, considering first the lower and then the upper limit of the respective variability range.
In a second phase, to obtain data on the use of CTZ monotherapy, the base case results were recalculated, replacing the ACR response rates estimated by Orme et al. [20] with those obtained in another meta-analysis, whose objectives also included estimating the efficacy of monotherapy in patients who are intolerant to MTX, or for whom it is inappropriate to continue treatment with MTX [30]. In that meta-analysis, a specific efficacy value (ACR 20, 50, and 70) was calculated for TCZ and a mean value was calculated for TNF- $\alpha$ inhibitors among which CTZ was considered, in addition to ETA and ADA. For the latter, an overall 6-month cost of $€ 6084.06$ was considered. In line with the methods adopted for the other biologics, the cost was composed of $€ 100.48$ for monitoring and $€ 5983.58$ for purchase of the biologic (Table 3). For the sc bDMARDs, no cost was considered for administration.

Sensitivity analysis on monitoring and administration costs was not performed as they have a minimal impact on overall costs, and therefore, even significant changes in the base values would not have produced any 
Table 5 NNT

\begin{tabular}{lllll}
\hline NNT vs. placebo & TCZ (iv) & TCZ $(\mathbf{s c})$ & ETN (sc) & ADA (sc) \\
\hline ACR criteria & & & & \\
ACR 20 & 1.49 & 1.49 & 1.93 & 3.26 \\
ACR 50 & 1.45 & 1.45 & 2.47 & 5.78 \\
ACR 70 & 2.40 & 2.40 & 5.10 & 8.40 \\
EULAR criteria & & & \\
Moderate response & 2.33 & 2.33 & 4.76 & 3.85 \\
Good response & 2.04 & 2.04 & 7.14 & 5.26 \\
\hline
\end{tabular}

$A C R$ American College of Rheumatology, $A D A$ adalimumab, ETN etanercept, EULAR European League Against Rheumatism, iv intravenous, sc subcutaneous, $T C Z$ tocilizumab

differences that would substantially affect the base case results. For different reasons, sensitivity analysis for the cost of pharmacological treatment was not carried out. In the base case, the purchase cost net of compulsory legal discounts and gross of any other discounts granted to hospital facilities was used. As this latter type of discount is hard to quantify, it was preferred to not consider alternative scenarios to the base case, which undoubtedly would not have reflected the actual situation.

\section{Compliance with Ethics Guidelines}

This article is based on previously conducted studies and does not involve any new studies of human or animal subjects performed by any of the authors.

\section{RESULTS}

\section{NNT (Efficacy)}

Table 5 shows two separate series of NNT for TCZ (iv/sc), ADA, and ETA. The first series was calculated using ACR criteria, while EULAR criteria were used for the second. In both cases, TCZ (iv/sc) had a lower NNT (higher efficacy) than the other agents. The difference in the values observed for ETN was more pronounced using EULAR criteria, whereas in the comparison with ADA, the most sensitive differences were observed with ACR criteria.

\section{Cost of Treatment}

Table 6 shows the mean 6-month cost per treated patient, which is the sum of the ex-factory drug price plus the costs of administration and monitoring (these last two expense items only have a minimal impact on the overall cost (range 1.5-4.8\%). ETN had the lowest treatment cost (€6402.19), followed by ADA (€6698.84), TCZ sc (€6887.61), and TCZ iv (€7130.83). The differences compared to ETN vary from a minimum of approximately $€ 300$ (vs. ADA) to a maximum of about $€ 700$ (vs. TCZ iv).

\section{Cost for NNT}

Figures 1 and 2 show the mean cost per NNT calculated using ACR or EULAR response 
Table 6 Mean 6-month costs of treatment per patient

\begin{tabular}{lrrrr}
\hline Costs & TCZ (iv) & TCZ $(\mathbf{s c})$ & ETN (sc) & ADA (sc) \\
\hline Administration & $€ 69.72$ & $€ 0.00$ & $€ 0.00$ & $€ 0.00$ \\
Monitoring & $€ 270.46$ & $€ 100.48$ & $€ 100.48$ & $€ 100.48$ \\
Medicinal product & $€ 6790.65$ & $€ 6787.13$ & $€ 6301.71$ & $€ 6598.36$ \\
Total & $€ 7130.83$ & $€ 6887.61$ & $€ 6402.19$ & $€ 6698.84$ \\
\hline
\end{tabular}

$A D A$ adalimumab, ETN etanercept, iv intravenous, sc subcutaneous, $T C Z$ tocilizumab

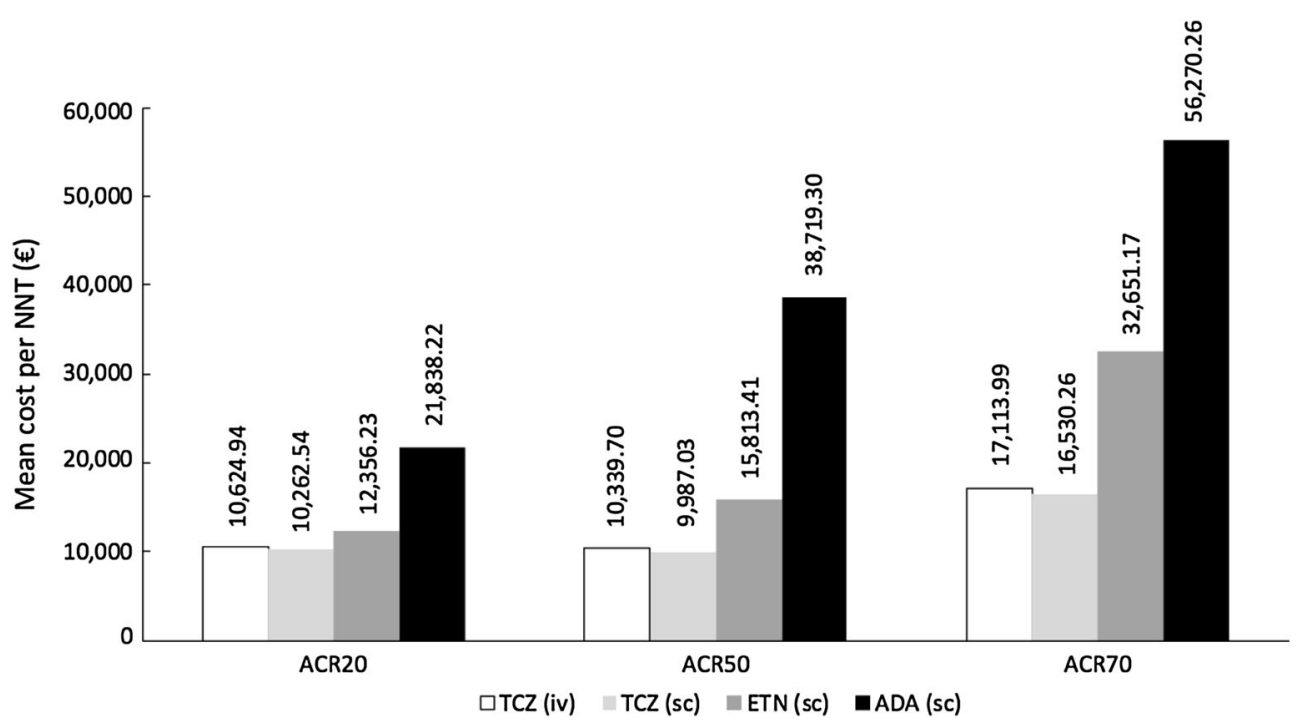

Fig. 1 Mean cost for the NNT: ACR criteria. ACR American College of Rheumatology, ADA adalimumab, ETN etanercept, $N N T$ number needed to treat, $i v$ intravenous, sc subcutaneous, $T C Z$ tocilizumab

criteria. In terms of the percentage of patients achieving ACR response $(20,50$, or 70$)$, TCZ sc had the lowest cost for NNT. Despite having higher administration and monitoring costs, iv TCZ showed lower mean costs for the NNT than ETN or ADA. The greater the clinical improvement according to ACR $(20,50$, or 70$)$ criteria, the greater the cost for the NNT calculated for TCZ (sc/iv) and the cost calculated for ETN or ADA. The mean cost for NNT calculated using EULAR response criteria showed that TCZ sc was the best treatment option, followed by TCZ iv. The differences compared to ETN and ADA were significant and related with the level of efficacy.

\section{Sensitivity Analysis}

Table 7 shows the results of the sensitivity analysis carried out in the light of changes in efficacy rates in relation to the limits of the corresponding variability ranges. In almost all comparisons, TCZ was associated with the lowest mean costs for NNT, with the exception of the case considering the upper limit of the confidence interval for the EULAR criteria, where ETN appeared to be the most cost-effective option. Table 8 shows the results of the sensitivity analysis using efficacy data of the meta-analysis conducted by Buckley et al. [29]. In this comparison, TCZ (sc/iv) had the lowest mean 


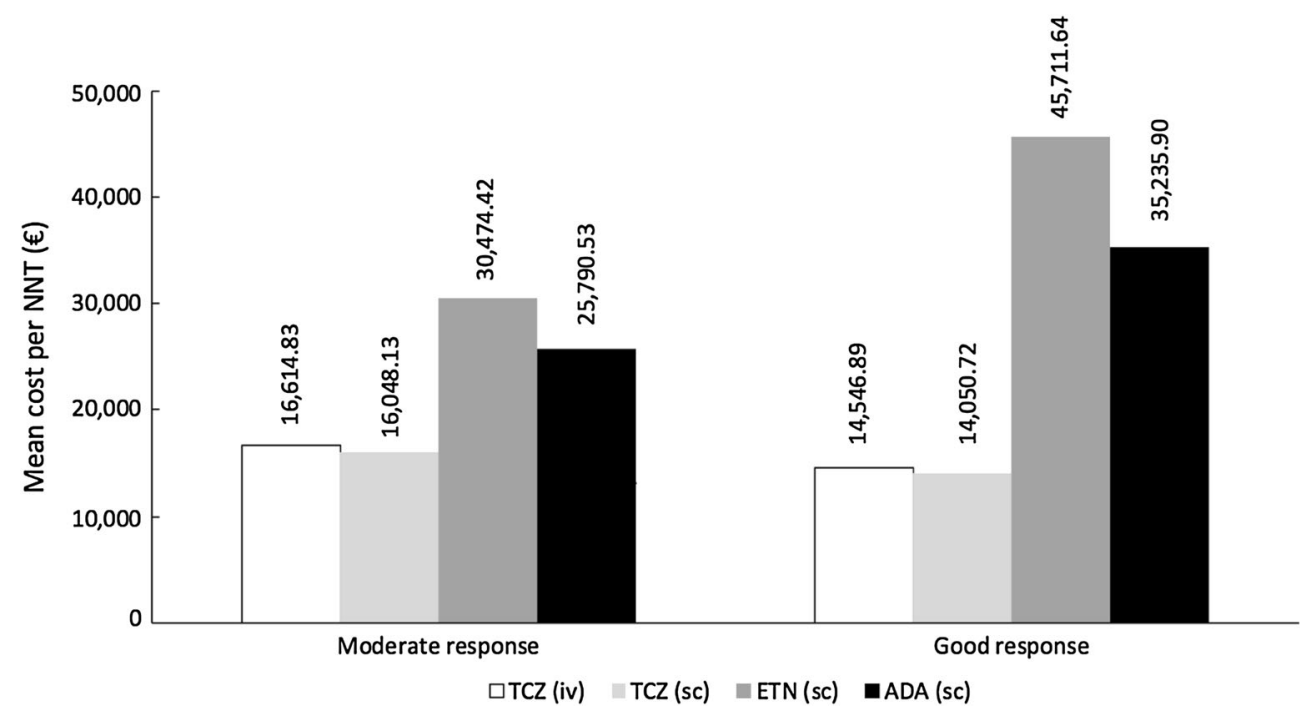

Fig. 2 Mean cost for the NNT: EULAR criteria. $A C R$ American College of Rheumatology, $A D A$ adalimumab,

Rheumatism, $N N T$ number needed to treat, iv intravenous, $E T N$ etanercept, EULAR European League Against sc subcutaneous, $T C Z$ tocilizumab

Table 7 Sensitivity analysis (efficacy data variation) $[19,20]$

\begin{tabular}{lrrll}
\hline Criteria for the NNT & TCZ (iv) & TCZ (sc) & ETN (sc) & ADA (sc) \\
\hline ACR criteria & & & & \\
ACR lower limit & $€ 14,261.66$ & $€ 13,775.22$ & $€ 18,566.35$ & $€ 31,417.56$ \\
ACR 20 upper limit & $€ 9484.00$ & $€ 9160.52$ & $€ 9731.33$ & $€ 16,680.11$ \\
ACR 50 lower limit & $€ 26,098.84$ & $€ 25,208.65$ & $€ 36,812.59$ & $€ 77,907.51$ \\
ACR 50 upper limit & $€ 7986.53$ & $€ 7714.12$ & $€ 9219.15$ & $€ 21,570.26$ \\
ACR 70 lower limit & $€ 148,535.19$ & $€ 143,468.92$ & $€ 237,137.12$ & $€ 223,272.34$ \\
ACR 70 upper limit & $€ 7416.06$ & $€ 7163.11$ & $€ 7170.45$ & $€ 16,881.08$ \\
EULAR criteria & & & & \\
Moderate response lower limit & $€ 10,197.09$ & $€ 9849.28$ & $€ 128,043.80$ & $€ 25,790.53$ \\
Moderate response upper limit & $€ 142,616.60$ & $€ 137,752.20$ & $€ 128,043.80$ & $€ 167,471.00$ \\
Good response lower limit & $€ 23,032.58$ & $€ 22,246.98$ & N/A & N/A \\
Good response upper limit & $€ 31,019.11$ & $€ 29,961.10$ & $€ 29,129.96$ & $€ 51,514.08$ \\
\hline
\end{tabular}

$A C R$ American College of Rheumatology, $A D A$ adalimumab, ETN etanercept, EULAR European League Against Rheumatism, $N / A$ not applicable, $N N T$ number needed to treat, $i v$ intravenous, $s c$ subcutaneous, $T C Z$ tocilizumab

cost for NNT. The cost-effectiveness of TCZ was also confirmed compared to CTZ, which was the biologic with the lowest treatment costs in the six-month observation period.

\section{DISCUSSION}

The present analysis used the NNT as a synthetic indicator to assess the clinical 
Table 8 Sensitivity analysis (Buckley et al. [29])

\begin{tabular}{lllllll}
\hline \multicolumn{1}{l}{} & Placebo & TCZ (iv) & TCZ (sc) & ETN (sc) & ADA (sc) & CTZ (sc) \\
\hline Efficacy & & & & & & \\
ACR 20 & $17.30 \%$ & $72.90 \%$ & $72.90 \%$ & $58.30 \%$ & $58.30 \%$ & $58.30 \%$ \\
ACR 50 & $6.20 \%$ & $50.50 \%$ & $50.50 \%$ & $30.50 \%$ & $30.50 \%$ & $30.50 \%$ \\
ACR 70 & $1.30 \%$ & $28.80 \%$ & $28.80 \%$ & $15.50 \%$ & $15.50 \%$ & $15.50 \%$ \\
NNT (calculated compared to placebo) & & & & \\
ACR 20 & N/A & 1.8 & 1.8 & 2.44 & 2.44 & 2.44 \\
ACR 50 & N/A & 2.26 & 2.26 & 4.12 & 4.12 & 4.12 \\
ACR 70 & N/A & 3.64 & 3.64 & 7.04 & 7.04 & 7.04 \\
Cost for the NNT & & & & & \\
ACR 20 & N/A & $€ 12,835.49$ & $€ 12,397.70$ & $€ 15,621.34$ & $€ 16,345.17$ & $€ 14,845.11$ \\
ACR 50 & N/A & $€ 16,115.68$ & $€ 15,566.00$ & $€ 26,377.02$ & $€ 27,599.22$ & $€ 25,066.33$ \\
ACR 70 & N/A & $€ 25,956.22$ & $€ 25,070.90$ & $€ 45,071.42$ & $€ 47,159.83$ & $€ 42,831.78$ \\
\hline
\end{tabular}

$A C R$ American College of Rheumatology, ADA adalimumab, CTZ certolizumab, ETN etanercept, $N / A$ not applicable, $N N T$ number needed to treat, $i v$ intravenous, $s c$ subcutaneous, $T C Z$ tocilizumab

benefits and costs associated with the use of different monotherapies (ADA, ETA, CTZ, and TCZ) in the treatment of patients who are intolerant to MTX, or for whom it is no longer appropriate to continue therapy with MTX. The NNT was calculated using both ACR response rates, indicated in the meta-analysis conducted by Orme et al. [20], and EULAR criteria, obtained from the meta-analysis conducted by NICE in its recent appraisal [19]. For each bDMARD, we calculated the respective 6-month costs for purchase, administration, and monitoring by the NHS.

TCZ had the lowest mean cost for the NNT calculated with both response criteria, which were slightly higher for the iv formulation after administration and monitoring. The costs calculated for the other sc bDMARDs were significantly higher. Hence, it was seen that the greater the clinical improvement, according to $\operatorname{ACR}(20,50$, or 70$)$ or EULAR criteria (moderate or good response), the greater the difference in NNT costs in favor of TCZ (sc/iv).

While it is worthwhile to discuss the results of economic analysis by comparing them with those already published, to the best of our knowledge there are no other similar assessments in this specific patient population. However, three cost-utility analyses that estimated the incremental cost per QALY for TCZ compared to other TNF- $\alpha$ inhibitors are available. In the first study, carried out in Greece, TCZ had an incremental cost per QALY of $€ 28,837$ compared to the use of other TNF- $\alpha$ inhibitors in the treatment of patients intolerant to MTX or for whom it was not appropriate to continue treatment with MTX [31]. The second analysis, carried out in the United States, compared monotherapy with TCZ or ADA for the treatment of patients with RA for whom treatment with MTX was not appropriate [32]. The authors, on the basis of 
the results of the ADACTA direct comparison clinical study, calculated an incremental cost per QALY of US $\$ 36,944$ in favor of TCZ compared with ADA. The third study [33], from the UK, evaluated the cost-utility of TCZ in addition to the current sequence of treatments envisaged for RA. In that report, two scenarios were explored: one for patients for whom MTX is contraindicated and one for tolerant patients. For each of these scenarios, three different treatment strategies were compared: (1) standard of care (consisting a sequence of the most commonly administered biologics), (2) TCZ as first-line therapy, and (3) TCZ as second-line therapy. In patients for whom MTX is contraindicated, TCZ was found to be cost-effective as both first- and second-line therapy, whereas in MTX-tolerant patients the strategy involving the addition of TCZ (first- or second-line) was found to be similar to that determined by the standard of care. All three analyses concluded that TCZ was a cost-effective option in patients with RA for whom biologic monotherapy was indicated, thus confirming the results of the present analysis with different methods.

To analyze the limits of our study, as previously mentioned the two meta-analyses considered did not allow determination of clinical outcomes expressed in terms of survival simple or QALY, essentially changing the choice of assessment method to the cost for the NNT as an indicator of cost-effectiveness. For this reason, we compared the bDMARDs by calculating the number of subjects needed to be treated to achieve a specific therapeutic target (ACR/ EULAR). With this indicator, it was possible to determine an order of preference among the bDMARDs based on cost-effectiveness.

A further aspect that needs to be discussed is the efficacy data used to calculate the NNT. Although the two meta-analyses $[19,20]$ evaluated a large number of randomized clinical studies, the efficacy data are characterized by a broad range of variability. Given this uncertainty, sensitivity analysis was required to evaluate its impact on the final results. It was also seen that by simultaneously considering the upper or lower extremities of the efficacy rate variability range (ACR 20, 50, 70 , moderate or good response), the results of the base case were more or less confirmed. Additionally, as confirmation of the clinical data used herein, a subsequent analysis conducted versus alternative monotherapies (ADA, ETA, CTZ) showed that TCZ had a greater likelihood of being the most effective treatment in inducing ACR 20, 50, and 70 responses [34].

Hence, it must be pointed out that the efficacy of TCZ, as mentioned in both meta-analyses, must be interpreted with a caution given the direct effect that the agent has on CRP values, as the latter is a component of the ACR and EULAR composite endpoints on which the comparison was based. To confirm the validity of the results of the meta-analyses, it is important to remember that in some of the most recent clinical studies investigating the efficacy of TCZ monotherapy (ACT-RAY and ADACTA studies) that the composite endpoints were calculated using ESR values only. This avoids potential bias due to CRP values, but at the same time confirmed the greater efficacy of TCZ $[35,36]$. Hence, a post hoc analysis of the ADACTA study [36], which used the Clinical Disease Activity Index (CDAI) criterion (a parameter that does not consider values such as CRP or ESR to evaluate disease activity and remission rates), also confirmed the efficacy of TCZ, in agreement with the findings obtained in the ADACTA study [35].

Given the limited effect on total costs, no sensitivity analysis was conducted for 
monitoring and administration of drugs. To allow homogeneous comparison for the biologic agents, the cost considered was the NHS purchase cost net of compulsory legal discounts only. Because it is difficult to identify the actual drug cost that takes into account all the discounts granted to hospital structures, it was considered unreasonable to conduct sensitivity analysis on this parameter.

As this economic analysis was conducted from the Italian NHS perspective, the present results may not be directly generalized to other countries with different drug costs and healthcare services reimbursement. Furthermore, the analysis considered only the economic impact of a few direct medical costs (drugs, administration, and monitoring).

\section{CONCLUSIONS}

The results of the present economic assessment, estimating the mean costs of NNT showed that TCZ represents a cost-effective therapeutic option in an NHS perspective compared to other TNF- $\alpha$ inhibitors (ADA, ETA, CTZ) as first-line monotherapy for patients who are intolerant to MTX, or for whom it is inappropriate to continue treatment with MTX.

\section{ACKNOWLEDGMENTS}

This research was made possible by an educational grant from Roche SpA. The article processing charges and open access fee for this publication were funded by Health Publishing and Services Srl. All named authors meet the International Committee of Medical Journal Editors (ICMJE) criteria for authorship for this manuscript, take responsibility for the integrity of the work as a whole, and have given final approval to the version to be published.
Disclosures. Alberto Batticciotto, Roberto Ravasio, Marta Riva, and Piercarlo Sarzi-Puttini declare that they have no conflicts of interest in the research.

Compliance with Ethics Guidelines. This article is based on previously conducted studies and does not involve any new studies of human or animal subjects performed by any of the authors.

Open Access. zThis article is distributed under the terms of the Creative Commons Attribution-NonCommercial 4.0 International License (http://creativecommons.org/licenses/ by-nc/4.0/), which permits any noncommercial use, distribution, and reproduction in any medium, provided you give appropriate credit to the original author(s) and the source, provide a link to the Creative Commons license, and indicate if changes were made.

\section{REFERENCES}

1. Gibofsky A. Overview of epidemiology, pathophysiology, and diagnosis of rheumatoid arthritis. Am J Manag Care. 2012;18(13 Suppl):S295-302.

2. Gibofsky A. Epidemiology, pathophysiology, and diagnosis of rheumatoid arthritis: a synopsis. Am J Manag Care. 2014;20(7 Suppl):S128-35.

3. Kvien TK. Epidemiology and burden of illness of rheumatoid arthritis. Pharmacoeconomics. 2004;22(2 Suppl 1):1-12.

4. Singh JA, Furst DE, Bharat A, Curtis JR, Kavanaugh $\mathrm{AF}$, Kremer JM, et al. 2012 update of the 2008 American College of Rheumatology recommendations for the use of disease-modifying antirheumatic drugs and biologic agents in the treatment of rheumatoid arthritis. Arthritis Care Res (Hoboken). 2012;64(5):625-39.

5. Cerra C, Ravasio R, Polcaro F. Il costo dell'Artrite Reumatoide: l'esperienza dell'ASL della Provincia di Pavia. Giornale Italiano di Health Technol Assess. 2009;2(3):111-7. 
6. Shichikawa $\mathrm{K}$, Inoue $\mathrm{K}$, Hirota $\mathrm{S}$, Maeda $\mathrm{A}$, Ota $\mathrm{H}$, Kimura $\mathrm{M}$, et al. Changes in the incidence and prevalence of rheumatoid arthritis in Kamitonda, Wakayama, Japan, 1965-1996. Ann Rheum Dis. 1999;58(12):751-6.

7. Cimmino MA, Parisi M, Moggiana G, Mela GS, Accardo S. Prevalence of rheumatoid arthritis in Italy: the Chiavari Study. Ann Rheum Dis. 1998;57(5):315-8.

8. Boonen A, Mau W. The economic burden of disease: comparison between rheumatoid arthritis and ankylosing spondylitis. Clin Exp Rheumatol. 2009;27(4 Suppl 55):S112-7.

9. NICE. Rheumatoid arthritis (CG79): full guideline. London, UK: NICE; 2009. http://guidance.nice.org. uk/CG79/Guidance. Accessed 20 Apr 2016.

10. Thwaites C, Finney A. Rheumatoid arthritis. 2: exploring treatment options to achieve early control and remission. Nurs Times. 2010;106(10):18-20.

11. Caporali R, Conti F, Alivernini S, Atzeni F, Seriolo B, Cutolo $\mathrm{M}$, et al. Recommendations for the use of biologic therapy in rheumatoid arthritis: update from the Italian Society for Rheumatology I. Efficacy. Clin Exp Rheumatol. 2011;29(3 Suppl 66):S7-14.

12. Emery P, Breedveld FC, Dougados M, Kalden JR, Schiff MH, Smolen JS. Early referral recommendation for newly diagnosed rheumatoid arthritis: evidence based development of a clinical guide. Ann Rheum Dis. 2002;61(4):290-7.

13. Kuek A, Hazleman BL, Ostor AJ. Immune-mediated inflammatory diseases (IMIDs) and biologic therapy: a medical revolution. Postgrad Med J. 2007;83(978):251-60.

14. Lee DM, Weinblatt ME. Rheumatoid arthritis. Lancet. 2001;358(9285):903-11.

15. Nell VP, Machold KP, Eberl G, Stamm TA, Uffmann $\mathrm{M}$, Smolen JS. Benefit of very early referral and very early therapy with disease-modifying anti-rheumatic drugs in patients with early rheumatoid arthritis. Rheumatology (Oxford). 2004;43(7):906-14.

16. Conti F, Scrivo R. Il follow-up del paziente con artrite reumatoide di lunga durata. Focus Anno XIV. 2011;1:1-48.

17. Aletaha D, Smolen J. The simplified disease activity index (SDAI) and the clinical disease activity index (CDAI): a review of their usefulness and validity in rheumatoid arthritis. Clin Exp Rheumatol. 2005;23(5 Suppl 39):S100-8.
18. Prevoo ML, van't Hof MA, Kuper HH, van Leeuwen MA, van de Putte LB, van Riel PL. Modified disease activity scores that include twenty-eight-joint counts. Development and validation in a prospective longitudinal study of patients with rheumatoid arthritis. Arthritis Rheum. 1995;38(1):44-8.

19. NICE. Adalimumab, etanercept, infliximab, certolizumab pegol, golimumab, tocilizumab and abatacept for rheumatoid arthritis not previously treated with DMARDs or after conventional DMARDs only have failed. Technology appraisal guidance. http://www.nice.org.uk/guidance/ta375 (2016). Accessed Apr 2016.

20. Orme ME, Macgilchrist KS, Mitchell S, Spurden D, Bird A. Systematic review and network meta-analysis of combination and monotherapy treatments in disease-modifying antirheumatic drug-experienced patients with rheumatoid arthritis: analysis of American College of Rheumatology criteria scores 20, 50, and 70 . Biologics. 2012;6:429-64.

21. The AIES working group (coordinated by G. Fattore). Proposta di linee guida per la valutazione economica degli interventi sanitari in Italia. PharmacoEcon Ital Res Artic. 2009;11(2):83-93.

22. Barra L, Pope JE, Payne M. Real-world anti-tumor necrosis factor treatment in rheumatoid arthritis, psoriatic arthritis, and ankylosing spondylitis: cost-effectiveness based on number needed to treat to improve health assessment questionnaire. J Rheumatol. 2009;36(7):1421-8.

23. Kristensen LE, Christensen R, Bliddal H, Geborek P, Danneskiold-Samsoe B, Saxne T. The number needed to treat for adalimumab, etanercept, and infliximab based on ACR50 response in three randomized controlled trials on established rheumatoid arthritis: a systematic literature review. Scand J Rheumatol. 2007;36(6):411-7.

24. NICE. Guide to the methods of technology appraisal. 2013. http://www.nice.org.uk/about nice/howwework/devnicetech/guidetothemethod softechnologyappraisal.jsp. Accessed Oct 2014.

25. Canadian Agency for Drugs and Technologies in Health. Guidelines for the Economic Evaluation of Health Technologies: Canada rE. http:// www.inahta.org/upload/HTA_resources/AboutHTA_ Guidelines_for_the_Economic_Evaluation_of_Health_ Technologies.pdf. Accessed Oct 2014.

26. Specialist outpatient healthcare services. Ordinary supplement no. 8 to the Official Gazette. General series no. 23 of 20/01/2013.

27. Poster presented at ISPOR 18th Annual European Congress, 7-11 November 2015 Milan, Italy. 
28. AIES, Associazione Italiana di Economia Sanitaria. Proposte di linee guida per la valutazione economica degli interventi sanitari. Pharmacoecon Ital Res Artic. 2009;11(2):89-93.

29. Buckley F, Finckh A, Huizinga TW, Dejonckheere F, Jansen JP. Comparative efficacy of novel DMARDs as monotherapy and in combination with methotrexate in rheumatoid arthritis patients with inadequate response to conventional DMARDs: a network aeta-analysis. J Manag Care Spec Pharm. 2015;21(5):409-23.

30. Athanasakis K, Tarantilis F, Tsalapati K, Konstantopoulou T, Vritzali E, Kyriopoulos J. Cost-utility analysis of tocilizumab monotherapy in first line versus standard of care for the treatment of rheumatoid arthritis in Greece. Rheumatol Int. 2015;35(9):1489-95.

31. Carlson JJ, Ogale S, Dejonckheere F, Sullivan SD. Economic evaluation of tocilizumab monotherapy compared to adalimumab monotherapy in the treatment of severe active rheumatoid arthritis. Value Health. 2015;18(2):173-9.

32. Diamantopoulos A, Finckh A, Huizinga T, Sungher DK, Sawyer L, Neto D, et al. Tocilizumab in the treatment of rheumatoid arthritis: a cost-effectiveness analysis in the UK. Pharmacoeconomics. 2014;32(8):775-87.
33. Migliore A, Bizzi E, Egan CG, Bernardi M, Petrella L. Efficacy of biological agents administered as monotherapy in rheumatoid arthritis: a Bayesian mixed-treatment comparison analysis. Ther Clin Risk Manag. 2015;11:1325-35.

34. Gabay C, Emery P, van Vollenhoven R, Dikranian A, Alten R, Pavelka K, et al. Tocilizumab monotherapy versus adalimumab monotherapy for treatment of rheumatoid arthritis (ADACTA): a randomised, double-blind, controlled phase 4 trial. Lancet. 2013;381(9877):1541-50.

35. Dougados M, Kissel K, Sheeran T, Tak PP, Conaghan PG, Mola EM, et al. Adding tocilizumab or switching to tocilizumab monotherapy in methotrexate inadequate responders: 24-week symptomatic and structural results of a 2-year randomised controlled strategy trial in rheumatoid arthritis (ACT-RAY). Ann Rheum Dis. 2013;72(1):43-50.

36. Gabay C, Emery P, van Vollenhoven R, Dikranian A, Alten R, Klearman M, et al. Tocilizumab (TCZ) monotherapy is superior to adalimumab (ADA) monotherapy in reducing disease activity in patients with rheumatoid arthritis (RA): 24-week data from the phase 4 adacta trial. Ann Rheum Dis. 2013;71(Suppl 3):152. 